\title{
SOMATOTYPES IN SPORT
}

\section{Teodor TÓTH*, Monika MICHALÍKOVÁ*, Lucia BEDNARČíKOVÁ*, Jozef ŽIVČÁK*, Peter KNEPPO**}

\author{
*Faculty of Mechanical Engineering, Department of Biomedical Engineering and Measurement, \\ Technical University, Letná 9, Košice, Slovak Republic \\ ${ }^{*}$ Faculty of Biomedical Engineering, Department of Biomedical Technology, \\ Czech Technical University, Nám. Sítná 3105, Kladno, Czech Republic
}

teodor.toth@tuke.sk, monika.michalikova@tuke.sk, lucia.bednarcikova@tuke.sk, jozef.zivcak@tuke.sk, kneppo@fbmi.cvut.cz

\begin{abstract}
The submitted article deals with the evaluation of the somatotype of persons and determination of a suitable somatotype for selected sports. In the introduction the method for determining and evaluating a somatotype according to Carter and Heath is characterised. The processes used for calculating the individual components - endomorphy, mesomorphy, ectomorphy - are presented as well as a description of these elements. The calculated components are subsequently put into a somatograph. The evaluation of a somatotype is of great benefit and offers a guideline with the selection of sporting activities; it subsequently helps assign athletes into a suitable position where they will be able to best develop their talents in view of their bodily construction. In this work two types of sports are evaluated basketball and bodybuilding. With each sport the measurements which give the prerequisites for the given sport are presented. The selection of the presented sports was made with regard to the different requirements and demands in the scope of bodily constitution. The aim of the presented paper is to assess physical parameters of subjects groups in relation to selected sports (basketball and bodybuilding). Based on the body constitution to determine the conditions for developing the physical condition and success in the appointed sports. Another objective is to compare the rating form and equation methods for somatotype determination. The sample consist 32 subjects with age between 22-28 years of both sexes, who are dedicated to basketball, or bodybuilding at amateur level.
\end{abstract}

Key words: Somatotypes, Somatometry, Sport

\section{INTRODUCTION}

Somatometry is a fundamental research method in anthropology. It involves the measurement of bodily proportions and sizes in living individuals. Before the start of measuring it is necessary to ask three basic questions:

- What is necessary to measure and evaluate and what kind of data should be obtained by measuring?

- How will the given dimensions be obtained? (determination of anthropometric points)

- What instruments should be chosen?

A somatotype is understood as the description of the current morphological condition of an individual, expressed through 3 numbers, where each of them represents one of the 3 basic components of body composition (Carter, 1996).

The values of the components and their mutual ratio express the specific individual variations in the shape and composition of a human body and its parts. Sheldon typoogy is a new version of somatotypology by classifying people into endomorphic, mesomorphic, and ectomorphic, based on many photographs and measurements of nude figures at Ivy League schools (Carter and Heath, 1990).

Division of somatotypes:

- Ectomorph: the slim and thin type, signs of slenderness predominate, fragility, weak bones and musculature, anterodorsal diameters small, sloped shoulders, a relatively short torso, relatively long limbs, not always a tall figure, a flat and narrow thorax, rounded arms, aliform protrusion of the shoulder blades, weak thighs and arms, fragile and long fingers, weak dry skin. Rapid energetic expenditure, few fat cells. Gains muscle mass poorly, requires less demanding training, longer pauses between series, a high intake of protein and sufficient rest (Carter and Heath, 1990).

- Endomorph: The chunky type with a large number of fat cells, rounded shapes, the appearance of softer musculature, anterodorsal diameters are balanced by the frontal diameter, the circumference of the waist is larger than that of the thorax, a large head, a wide face, short neck, rounded features of the shoulders, relatively short and weak limbs and fingers, relatively small feet and hands, relatively strong bones. Endomorphic types often have good potential for adding muscle, but have difficulty losing fat. Little activity leads to a risk of obesity and heart diseases (Carter and Heath, 1990).

- Mesomorph: the muscular type with a strong skeleton, sharp musculature relief, broad shoulders and thorax, muscular limbs, a firm stomach wall that does not protrude, a massive pelvis, good posture, medium fast energetic expenditure. Reacts to strength training with rapid accumulation of muscle mass (Carter and Heath, 1990, Isak, 2001).

The technique of somatotyping is used to appraise body shape and composition. The somatotype is defined as the quantification of the present shape and composition of the human body.

The Heath-Carter method of somatotyping is the most commonly used today. There are three ways of obtaining the somatotype.

- The anthropometric method, in which anthropometry is used to estimate the criterion somatotype.

- The photoscopic method, in which ratings are made from a standardized photograph.

- The anthropometric plus photoscopic method, which combines anthropometry and ratings from a photograph - it is the criterion method.

A somatotype is evaluated on the basis of three numbers - 
the first number indicates the endomorphic, the second number the mesomorphic and the third the ectomorphic component.

If a component is lower than 2.5 it is considered to be low, from 3.0 to 5.0 medium and from 5.5 to 7.0 as high. Values higher than 7.5 are considered as extreme. The calculated triplenumbers are applied to a spherical triangle (a somatograph) on which the peaks are like the marginal types, the centre the balanced types and inside the medium types.

\section{DETERMINATION OF A SOMATOTYPES}

For determination of a somatotype, it is necessary to obtain the following measurements:

- Body heigh $(B H)[\mathrm{cm}]$ - Taken against a height scale or stadiometer. Take height with the subject standing straight, against an upright wall or stadiometer, touching the wall with heels, buttocks and back. Orient the head in the Frankfort plane (the upper border of the ear opening and the lower border of the eye socket on a horizontal line), and the heels together. Instruct the subject to stretch upward and to take and hold a full breath. Lower the headboard until it firmly touches the vertex.

- Weight $(W)[\mathrm{kg}]$ - The subject, wearing minimal clothing, stands in the center of the scale platform. Record weight to the nearest tenth of a kilogram. A correction is made for clothing so that nude weight is used in subsequent calculations.

- Triceps skinfold (TS) [mm] - With the subject's arm hanging loosely in the anatomical position, raise a fold at the back of the arm at a level halfway on a line connecting the acromion and the olecranon processes.

- Subscapular skinfold (SbS) [mm] - Raise the subscapular skinfold on a line from the inferior angle of the scapula in a direction that is obliquely downwards and laterally at 45 degrees.

- Supraspinal skinfold $(S p S)[\mathrm{mm}]$ - Raise the fold 5-7 cm (depending on the size of the subject) above the anterior superior iliac spine on a line to the anterior axillary border and on a diagonal line going downwards and medially at 45 degrees.

- Calf skinfold (CS) [mm] - Raise a vertical skinfold on the medial side of the leg, at the level of the maximum girth of the calf.

- Width of the elbow joint $(E W)[\mathrm{cm}]$ - The width between the medial and lateral epicondyles of the humerus, with the shoulder and elbow flexed to 90 degrees. Apply the caliper at an angle approximately bisecting the angle of the elbow. Place firm pressure on the crossbars in order to compress the subcutaneous tissue.

- Width of the knee joint $(\mathrm{KW})[\mathrm{cm}]$ - Seat the subject with knee bent at a right angle. Measure the greatest distance between the lateral and medial epicondyles of the femur with firm pressure on the crossbars in order to compress the subcutaneous tissue.

- Circumference of the flexed bicep $(B C) \quad[\mathrm{cm}]$ - The subject flexes the shoulder to 90 degrees and the elbow to 45 degrees, clenches the hand, and maximally contracts the elbow flexors and extensors. Take the measurement at the greatest girth of the arm.

- Circumference of the calf muscle (CC) [cm] - The subject stands with feet slightly apart. Place the tape around the calf and measure the maximum circumference (Carter and Heath, 1990, Duquet, Carter, 2001).

All measurements are recorded in the measurements list.

There are two ways to calculate the anthropometric somatotype:

1. Enter the data into equations derived from the rating form (2.1).

2. Enter the data onto a somatotype rating form (2.2).

\subsection{Enter the data into equations derived from the rating form}

Endomorphy: relates to the relative fatness or relative thinness (slimness) of a person. The degree of endomorphy reflects the amount of subcutaneous fat and is placed on a continuum from the lowest to the highest values. The equation according to Carter and Heath (1990):

$E N=0.7182+0.1451(X)-0.00068\left(X^{2}\right)$

$+0.0000014\left(X^{3}\right)$

where:

$X=\frac{170,18 *(T S+S b S+S p S)}{B H}$

where: $B H, T S, S b S, S p S$ are from measurements list.

One degree of endomorphy corresponds approximately to $5 \%$ fat (Carter and Heath, 1990).

Mesomorphy: relates to the relative muscular and skeletal development relating to body height.

At first it is necessary to adjust the circumference of the biceps by subtracting the thickness of the skinfold of the triceps [cm]. The same is performed with the circumference of the calf skinfold.

The equation according to Carter and Heath:

$\begin{aligned} M=0.858(E W)+ & 0.061(K W)+0.188(B C) \\ & +0.161(C C)-0.131(B H)+4.5\end{aligned}$

where: $B H, E W, K W, B C, C C$ are from measurements list (Carter and Heath, 1990).

Ectomorphy: relates to the length of part of the body. Determination is based on the index of the ratio of height and the third power of the weight. A low value establishes the assumption of relative shortness of different bodily dimensions and a high one, in contrast, their relative length. It also evaluates the form and degree of the lengthwise distribution of endomorphy and mesomorphy.

$H W R=\frac{B H}{\sqrt[3]{W}}$

where: $\mathrm{BH}, \mathrm{W}$ are from measurements list.

This ratio is called height-weight ratio (HWR).

If HRW is (Carter and Heath, 1990):

- greater than or equal to 40.75: $E C=0.732(H W R)-28.58$.

- between 40.75-38.25: $E C=0.463(H W R)-17.63$.

- $\quad$ smaller than or equal to $38,25: E C=0.1$.

\subsection{Enter the data onto a somatotype rating form}

For somatotype rating is used the form in Fig. 1. The determination of somatotype is perform via following steps. 


\section{Endomorphy rating:}

- Record the measurements for each of the four skinfolds.

- Sum the triceps, subscapular, and supraspinale skinfolds; record the sum in the box opposite SUM3 SKINFOLDS. Correct for height by multiplying this sum by (170.18/height in $\mathrm{cm})$. See equation 2

- Circle the closest value from equation 2 in SKINFOLDS table to the right. The table is read vertically from low to high in columns and horizontally from left to right in rows. "Lower limit" and "upper limit" on the rows provide exact boundaries for each column. These values are circled only when SUM3 SKINFOLDS are within $1 \mathrm{~mm}$ of the limit. In most cases circle the value in the row "midpoint".

- In the row for endomorphy circle the value directly under the column for the value circled in previous step above.

Mesomorphy rating

- Record height and breadths of humerus and femur in the appropriate boxes. Make the corrections for skinfolds before recording girths of biceps and calf.

- In the height row directly to the right of the recorded value, circle the height value nearest to the measured height of the subject.

- For each bone breadth and girth circle the number nearest the measured value in the appropriate row.

- Deal only with columns, not numerical values for the two procedures below. Find the average deviation of the circled values for breadths and girths from the circled value in the height column. Column deviations to the right of the height column are positive deviations. Deviations to the left are negative deviations. (Circled values directly under the height column have deviations of zero and are ignored.) Calculate the algebraic sum of the \pm deviations (D). Use this formula: mesomorphy $=(D / 8)+4.0$. Round the obtained value of mesomorphy to the nearest one-half $(1 / 2)$ rating unit.

- In the row for mesomorphy circle the closest value for mesomorphy.

\begin{tabular}{|c|c|c|c|c|c|c|c|c|c|c|c|c|c|c|c|c|c|c|c|c|c|c|c|c|}
\hline \multirow{2}{*}{$\begin{array}{l}\text { Name } \\
\text { Date of Birth } \\
\text { Sex M M } \\
\text { Skinfolds Imm] }\end{array}$} & \multicolumn{18}{|c|}{ HEAT - CARTER SOMATOTYPE RATING FORM } & \multicolumn{6}{|c|}{$\begin{array}{l}\text { Date of measurement } \\
\text { Memo }\end{array}$} \\
\hline & & & & & & & & & & & & & & & & & & & & & & & & \\
\hline Triceps & 10.9 & 14.9 & 18.9 & 22.9 & 26.9 & 31.2 & 35.8 & 40.7 & 46.2 & 52.2 & 58.7 & 65.7 & 73.2 & 81.2 & 89.7 & 98.9 & 108.9 & 119.7 & 131.2 & 2143.7 & 157.2 & 171.9 & 187.9 & 204.0 \\
\hline Subscapular & 9.0 & 13.0 & 17.0 & 21.0 & 25.0 & 29.0 & 33.5 & 38.0 & 43.5 & 49.5 & 55.5 & 62.0 & 69.5 & 77.0 & 85.5 & 94.0 & 104.0 & 114.0 & 125.5 & 5137.0 & 150.5 & 164.0 & 180.0 & 196.0 \\
\hline $\begin{array}{l}\text { Supraspinal } \\
\text { SuM } \\
\text { Calf }\end{array}$ & 7.0 & 11.0 & 15.0 & 19.0 & 23.0 & 27.0 & 31.3 & 35.9 & 40.8 & 46.3 & 52.3 & 58.8 & 65.8 & 73.3 & 81.3 & 89.8 & 99.0 & 109.0 & 119.8 & 8131.3 & 143.8 & 157.3 & 172.0 & 188.0 \\
\hline ENDOMORPHY & 0.5 & 1 & 1.5 & 2 & 2.5 & 3 & 3.5 & 4 & 4.5 & 5 & 5.5 & 6 & 6.5 & 7 & 7.5 & 8 & 8.5 & 9 & 9.5 & 10 & 10.5 & 11 & 11.5 & 12 \\
\hline Heigh & 139.7 & 143.5 & 147.3 & 151.1 & 154.9 & 158.8 & 162.6 & 166.4 & 170.2 & 174 & 177.2 & 181.4 & 185.4 & 189.2 & 193 & 196.7 & 200.7 & 204.5 & 208.3 & 3212.12 & 215.9 & 220 & 224 & 227 \\
\hline Hum. width & 5.19 & 5.34 & 5.49 & 5.64 & 5.78 & 5.93 & 6.07 & 6.22 & 6.37 & 6.51 & 6.65 & 6.80 & 6.95 & 7.09 & 7.24 & 7.38 & 7.53 & 7.67 & 7.82 & 7.97 & 8.11 & 8.25 & 8.40 & 8.55 \\
\hline Femur width & 7.41 & 7.62 & 7.83 & 8.04 & 8.24 & 8.45 & 8.66 & 8.87 & 9.08 & 9.28 & 9.49 & 9.70 & 9.91 & 10.12 & 10.33 & 10.53 & 10.74 & 10.95 & 11.16 & 611.37 & 11.58 & 11.79 & 12.0 & 12.21 \\
\hline Biceps girth & 23.7 & 24.4 & 25.0 & 25.7 & 26.3 & 27.0 & 27.7 & 28.3 & 29.0 & 29.7 & 30.3 & 31.0 & 31.6 & 32.2 & 33.0 & 33.6 & 34.3 & 35.0 & 35.0 & 36.3 & 37.1 & 37.8 & 38.5 & 39.3 \\
\hline Calf girth & 27.7 & 28.5 & 29.3 & 30.1 & 30.8 & 31.6 & 32.4 & 33.2 & 33.9 & 34.7 & 35.5 & 36.3 & 37.1 & 37.8 & 38.6 & 39.4 & 40.2 & 41.0 & 41.0 & 42.6 & 43.4 & 77.2 & 45.0 & 45.8 \\
\hline MEZOMORPHY & 0.5 & 1 & 1.5 & 2 & 2.5 & 3 & 3.5 & 4 & 4.5 & 5 & 5.5 & 6 & 6.5 & 7 & 7.5 & 8 & 8.5 & 9 & & & & & & \\
\hline Weight & 39.65 & 40.74 & 41.43 & 42.13 & 42.82 & 43.48 & 44.18 & 44.94 & 45.53 & 46.23 & 46.92 & 47.584 & 48.25 & 48.94 & 49.63 & 50.33 & 50.99 & 51.68 & & & & & & \\
\hline & 39.60 & 40.2 & 41.09 & 41.79 & 42.44 & 43.14 & 43.84 & 44.50 & 45.20 & 45.90 & 46.52 & 47.24 & 47.94 & 48.60 & 49.29 & 49.99 & 50.66 & 51.34 & & & & & & \\
\hline $\begin{array}{l}\text { Heigh } \\
\text { weight }^{s}\end{array}$ & 39.45 & 39.75 & 40.75 & 41.44 & 42.14 & 42.83 & 43.49 & 44.19 & 44.95 & 45.54 & 46.24 & 46.93 & 47.59 & 48.26 & 48.95 & 49.64 & 50.34 & 51.00 & & & & & & \\
\hline ECTOMORPHY & 0.5 & 1 & 1.5 & 2 & 2.5 & 3 & 3.5 & 4 & 4.5 & 5 & 5.5 & 6 & 6.5 & 7 & 7.5 & 8 & 8.5 & 9 & & & & & & \\
\hline & & & & \begin{tabular}{|l|} 
END \\
\end{tabular} & & MEZ & & ECT & & & & & & & & & & & & & & & & \\
\hline & $\widehat{\text { SOMA }}$ & ATOTY & & & & & & & & & & & & & & & & & & & & & & \\
\hline
\end{tabular}

Fig. 1 Blank somatotype rating form

Ectomorphy rating:

- Record weight (kg).

- Obtain height divided by cube root of weight (HWR). Record HWR in the appropriate box.

- Circle the closest value in the HWR table to the right.

- In the row for ectomorphy circle the ectomorphy value directly below the circled HWR.

In the bottom section of the rating form in the row for Anthropometric Somatotype, record the circled ratings for Endomorphy, Mesomorphy and Ectomorphy. (Singh, Mehta,2009)

\section{PLOTTING THE SOMATOTYPE}

Traditionally, the three-number somatotype rating is plotted on a two-dimensional somatochart using $X, Y$ coordinates derived from the rating. The coordinates are calculated as follows:

$X=$ ectomorphy - endomorphy

$Y=2 x$ mesomorphy - (endomorphy + ectomorphy)

These points on the somatochart are called somatoplots (Fig. 2).

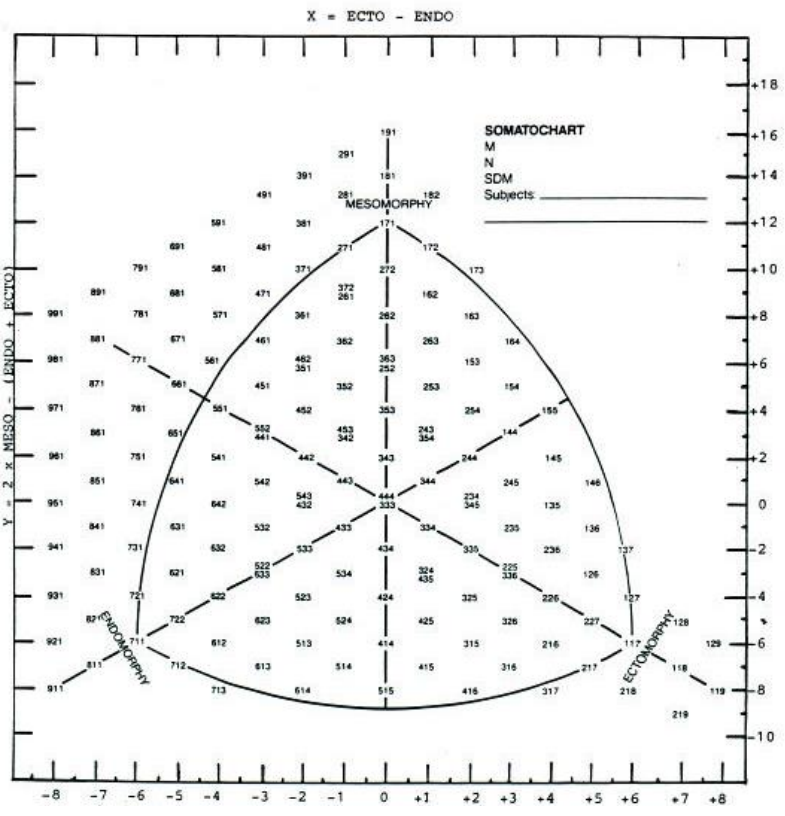

Fig. 2 The 2-D somatochart and $X, Y$ coordinates 


\section{RELATIONSHIP OF SOMATOTYPE TO MOVEMENT CAPABILITIES}

Presumptions regarding movement activities can be determined according to location on a somatograph (Fig. 3).

A. individuals with the most all-around talent for sports,

B. individuals with a talent for endurance sports and finesse,

C. a lower degree of talent due to a low mesomorphic component,

D. individuals with the worst prerequisites for sports activities,

E. individuals with the worst prerequisites for sports activities,

F. individuals with a very good prerequisites for power sports (http://www.sportvital.cz/zdravi/diagnostika/co-je-to-somatotyp-a-jakho-merime/).

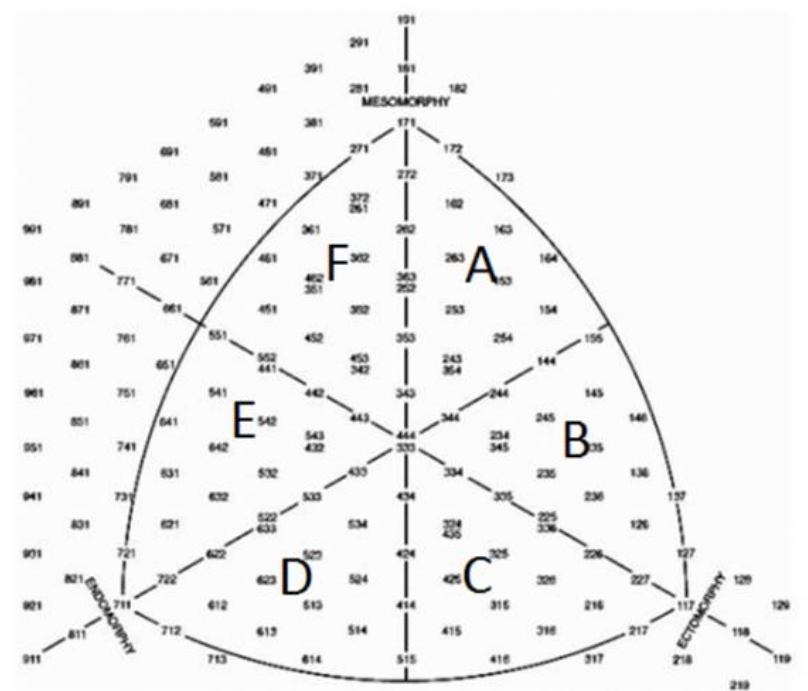

Fig. 3. Relationship of somatotype to movement capabilities

\subsection{Somatometry in basketball and bodybuilding}

In Department of biomedical engineering and measurement was assessed the sample of 32 subjects with age between 22-28 years of both sexes, who are dedicated to basketball (19 subjects), or bodybuilding (13 subjects) at amateur level.

The determination of the conditions for developing the physical condition and success in the appointed sports is based on the rating form and equation methods for somatotype determination.

For basketball a fluctuating intensity of the weight is typical. During a game a player runs perhaps $5-7 \mathrm{~km}$, jumps up approximately 40-50 times, changes directions up to $640 \mathrm{x}$ and changes speed up to 440x. Basketball is a collective sport with great differences in the somatotypes and physiologies among the player positions (Vitek, 2012).

Player positions in basketball:

- PG, point guard,

- SG, shooting guard,

- SF, small forward,

- PF, power forward,

- C, centre.

The tallest, with a large arm span, are used also during defensive and attacking activities and play in the post position, in the centre. Their primary domain is rebounding. Because of the significant bodily dimensions they are athletically the least efficient. The forwards (SF,PF) need to have a combination of the characteristics of the centre and the guards, and thus sufficient mass and strength for the ability of guarding the ball (the centre) but also quickness and leaping (guards). A guard is usually the smallest player with the lowest centre of gravity and is the best at keeping the ball (Komadel, 1985; Vitek, 2012; Novotny, 2013; Pavlik, 1999).

Anthropometric measurements in basketball:

- The arm span measured as the direct distance from the left and right dactylion point upon maximum spreading of the arms.

- Bodily fat from the endomorphy formula, where one degree of endomorphy corresponds to $5 \%$ fat

- Reach when standing is measured as the distance of the point of the dactylion from the ground, when arms are raised and stretched upward and the fingers are together and stretched upward.

- The length of the hand measured as the direct distance linking both points of the styloid point on the upper limb from the dactylion point.

- The width of the hand measured as the direct distance in the broadest area of the palm of the hand.

Tab. 1. Calculated values of somatotypes for basketball players

\begin{tabular}{|c|c|c|c|}
\hline No. & Ectomorphy & Mesomorphy & Endomorphy \\
\hline 1 & 4 & 1.344 & 4.6 \\
\hline 2 & 2.2664 & 4.5218 & 2.81 \\
\hline 3 & 3.32 & 2.392 & 4.422 \\
\hline 4 & 5 & 2.5 & 3.5 \\
\hline 5 & 2.7018 & 5.93 & 2.017 \\
\hline 6 & 5.07 & 1.64 & 3.56 \\
\hline 7 & 3.47 & 2.64 & 4.1 \\
\hline 8 & 2.99 & 2.699 & 1.019 \\
\hline 9 & 2.56 & 2.85 & 3.0182 \\
\hline 10 & 1.17 & 6.01 & 3.27 \\
\hline 11 & 4.34 & 2.74 & 3.38 \\
\hline 12 & 2.44 & 3.63 & 5.25 \\
\hline 13 & 2.4 & 2.9 & 3.1 \\
\hline 14 & 3.35 & 2.17 & 3.97 \\
\hline 15 & 3.42 & 1.61 & 3.27 \\
\hline 16 & 2.88 & 2.06 & 3.81 \\
\hline 17 & 2.74 & 2.68 & 2.92 \\
\hline 18 & 0.96 & 5.14 & 5.13 \\
\hline 19 & 2.85 & 2.58 & 3.18 \\
\hline & & & \\
\hline
\end{tabular}

Height rises according to the positions: the closer to the basket, the taller the player is, and this allows in connection with the jump and span of the arms the highest chance for a successful rebound. Weight likewise rises from the guards to the pivot man. In the position of the guards mobility is important, which is, in combination with the high mass, a unique phenomenon. Professionals in basketball do not have a high value of bodily fat because of preservation the lowest mass possible so that their mass does not inhibit their jumping and the time they spend in the air after a jump. Specific traits of guards are relatively small height and weight, a lower arm span and a low content of fat. Specific traits of forwards are a higher value of bodily height and weight than in the guards, a higher arm span but reduced mobility. Spe- 
cific traits of the pivot position are very high values of bodily height and weight and of reach when standing.

The study presents the most frequent averages of somatotypes of basketball players: $2-4.5-3.5$. The highest difference is in the values of mesomorphy and endomorphy. The average somatotype of the measured subjects were $3.7-2.7-2.7$ (Grasgruber and Cacek, 2008, Bernacíková, Kapounková and Novotný, 2010).

In Tab. 1 are calculated values of somatotypes for basketball players. The variance of somatotypes for basketbal players is affected with player position.

Bodybuilding is a sport which places emphasis on physical appearance, the shape of the muscles and the symmetry of the body. The goal of training is maximum musculature and physical symmetry with the lowest amount of preserved fat. The somatotype of bodybuilders is the closest to the ideal mesomorph and often achieves extreme mesomorphic values (Grasgruber and Cacek, 2008).

Tab. 2. Calculated values of somatotypes for bodybuilders

\begin{tabular}{|c|c|c|c|}
\hline No. & Ectomorphy & Mesomorphy & Endomorphy \\
\hline 1 & 1.406 & 2.377 & 5.713 \\
\hline 2 & 1.03621 & 2.07895 & 7.81341 \\
\hline 3 & 1.77 & 3.213 & 6.71 \\
\hline 4 & 0.59 & 4.501 & 7.696 \\
\hline 5 & 0.1 & 4.76 & 7.216 \\
\hline 6 & 2.4 & 3.5 & 3.07 \\
\hline 7 & 0.96 & 4.97 & 6.68 \\
\hline 8 & 2.32 & 3.038 & 5.25 \\
\hline 9 & -0.627 & 1.998 & 7.867 \\
\hline 10 & 2.41 & 4.27 & 5.72 \\
\hline 11 & 0.63 & 5.01 & 5.14 \\
\hline 12 & 1.22 & 4.47 & 6.07 \\
\hline 13 & 0.96 & 4.8 & 2.35 \\
\hline & & & \\
\hline
\end{tabular}

Anthropometric measurements in bodybuilding:

- The circumference of the thorax meter applied at the height of the nipples, arms located freely along the body, without inhaling.

- The circumference of the waist measured at the narrowest location, upon relaxation of the abdominal muscles (without exhaling).

- The circumference of the thigh upon bending the leg at a right angle, upon relaxation of the musculature.

- The circumference of the calf measured at the widest place, the knee is bent at a right angle.

- The circumference of the forearm measured at the widest place, the muscle flexed, the fist closed and tilted in the direction of the biceps.

- The circumference of the wrist is measured at the narrowest place, while the muscles are relaxed.

- The circumference of the biceps at the location of the largest volume.

From our measured results it was found that the measured subjects who participate in bodybuilding have a very low value of ectomorphy in the range of 0.63 to 1.22 , which is caused by higher values of fat and muscle mass. These attributes again cause a high number of endomorphy and mesomorphy. Subject no. 6 and 13 shows the lowest value of endomorphy, because of the differently oriented of the training (training for reduction of fat) (Tab. 2).

The measurements of basketball player are located in the centre of the somatograph so that it is not possible to assign them to categories. The measurements of bodybuilders belong to category F, thus, individuals with a talent for power sports (Fig. 4).

Example of somatotype evaluation with somatotype rating form is in Fig. 5

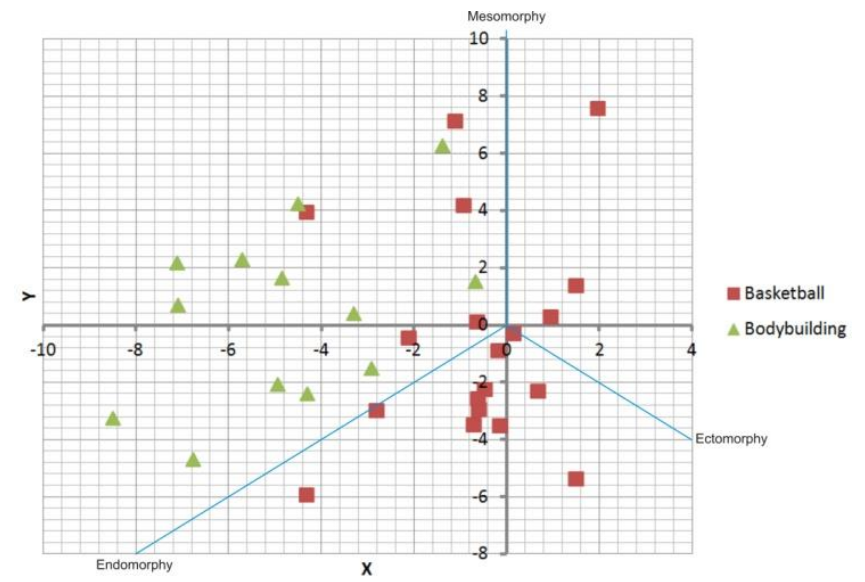

Fig. 4. Location of measured reults in somatograph

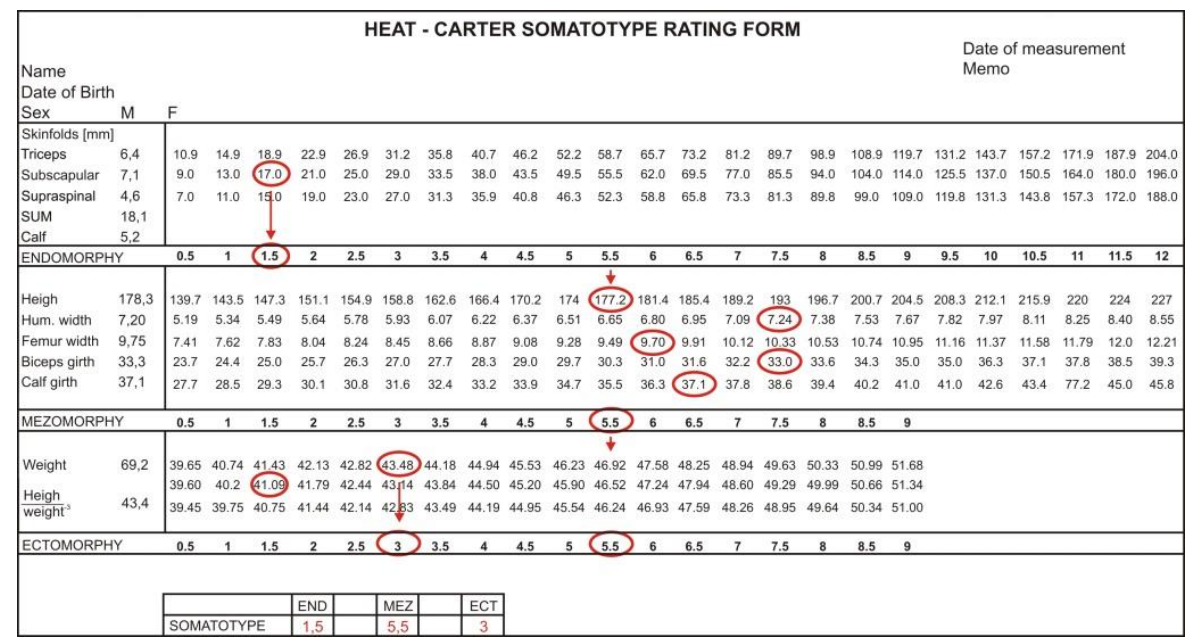

Fig. 5. Evaluated Heat - Carter somatotype rating form 


\section{RESULTS}

The main advantage of the equation method of calculating the somatotype is its accuracy. If the computer support is available (eg MS Excel, etc.), this method is faster than table form. Advantage of equation method is template creation for input parameters. In another case, the equation method is more difficult and time consuming. Table form method is less accurate, opened to random and rough errors. Its lower accuracy is caused by the need to choose the numerical value from the table - it is not considered directly with the measured value. It is also necessary to know and precede procedures and methodology in the evaluation using the table form. However, without the use of computer technology the table form method is faster and less difficult in terms of calculations.

The accuracy of both methods is affected by the measurement errors by the collection of the body dimensions, which depends on the experience of the person performing the measurements.

Group of bodybuilders is localized in endo - mesomorphic area. The average value of somatotype is $1.17-3.61$ to 6.03 . Basketball players group is distributed over the entire surface of somatoplot. Types of players in basketball at individual positions are diverse. For this reason, it is not determinative of an individual somatotype for basketball.

\section{REFERENCES}

1. Bernacíková M., Kapounková K., Novotný J. (2010), Basketball in: Masaryk University Brno multimedial internet book http://is.muni. $\mathrm{cz} / \mathrm{do} / \mathrm{rect} / \mathrm{el} / \mathrm{estud} / \mathrm{fsps} / \mathrm{ps} 10 / \mathrm{fyziol} / \mathrm{web} / \mathrm{sp}$ ort/hry-basketbal.html (in Czech)

2. Carter J.E.L., Heath, B.H. (1990), Somatotyping - Development and Applications, Cambridge, Cambridge University Press.

3. Carter L. (1996), Somatotyping, in: Norton K., Olds T. (Eds.): Anthropometrica, Chapt. 6, Sydney, University of New South Wales Press, 147-170.

4. Duquet W., Carter, J.E.L. (2001), Somatotyping, in: Eston R., Reilly T. (Eds.): Kinanthropometry and Exercise Physiology Laboratory Manual: Tests, Procedures and Data, Vol. 1, Anthropometry, Chapt. 2. London: E \& F.N. Spon.
5. Grasgruber P., Cacek J. (2008), Sport genes, in Computer Press Brno (in czech - Sportovni geny)

6. Hrstková, L. (2011) Somatotype Evaluation of Czech Woman Alpine Ski Team - Master thesis, in Masaryk University, Brno http://is.muni.cz/th/102301/fsps_m/?lang=en;id=214680 (in Czech)

7. Isak (2001), International Standards for Anthropometric Assessment, Underdale, International Society for the Advancement of Kinanthropometry.

8. Komadel, L. (1985), Sports Medicine, in SPN Bratislava (in Slovak

9. Norton K., Olds T. (1996), Anthropometrica: A Textbook of Body Measurement for Sports and Health Courses, UNSW Press.

10. Novotný J. (2013), Anthropology in sport - electronic teaching materials, in Masaryk University Brno, http://www.fsps.muni.cz/ حnovotny/Antropologie.pdf (in Czech).

11. Pavlík J. (1999), A body build as a sportsmans performance factor monograph, in Masaryk University Brno, http://home.pf.jcu.cz/ rvobr/somatotyp.htm (in Czech).

12. Rempel R. (1994). A modified somatotype assessment methodology, M.Sc. Thesis, Simon Fraser University, Burnaby, Canada.

13. Rosique J., Rebato E., Gonzalez Apraiz A., Pacheco J. L. (1994), Somatotype related to centripetal fat patterning of 8- to 19-year-old Basque boys and girls, American Journal of Human Biology, 6, 171-181.

14. Singh S. P., Mehta P. (2009), Human Body Measurements: Concepts And Applications, PHI Learning Pvt. Ltd.

15. Sodhi H. S. (1991), Sports Anthropometry (A Kinanthropometric Approach), Mohali, ANOVA Publications.

16. Trebuňová M., Gdovinová Z., Habalová V., Slabá, E. (2008), ACE I/D polymorphism in Alzheimer's disease, Central European Journal of Biology, 3 (1), 49-54.

17. Trebuňová M., Slabá E., Habalová V., Gdovinová Z. (2009), The Role of the $-427 \mathrm{~T} / \mathrm{C}$ Apolipoprotein E Promoter Polymorphism in the Pathogenesis of Alzheimer's Disease, Vascular Dementia and Mixed Dementia, Journal of Neural Transmission, 116 (3), 339-344.

18. Vitek L. (2012), What is somatotype and how do we measure it? http://www.sportvital.cz/zdravi/diagnostika/co-je-to-somatotyp-a-jakho-merime/ (in Czech)

This contribution is the result of the project implementation KEGA 031TUKE-4/2013: Prosthetic and orthotic proposal process in education. 